\title{
The Married Woman's First Child
}

\author{
By HENRIK MøRKEBERG
}

The Danish National Institute of Social Research.

Since the Second World War an ever-increasing number of surveys have been conducted to gather knowledge about social and economic factors connected with the fertility level. An increasing interest has especially been shown with respect to elucidating the demographic build-up of families on the background of the timing and spacing of the individual births in connection with the living conditions of the families.

In industrialized countries comparatively little stability in the annual birth rates in connection with the small-sized family has been observed. With the traditional demographic measures it has only to a limited extent been possible to predict these annual fluctuations. This is not only the case of the smaller annual fluctuations of the birth rate which has been observed. It even and in particular applies to the short-term increase in the birth rates immediately after the end of the Second World War and to a drastic fall in the birth rates in connection with the release of oral contraceptives which has been observed in western societies. As the traditional demographic methods have primarily been connected with the running registration of births, it has neither been possible to predict nor to explain the trends, the sizes or the durations of the changes mentioned. A better knowledge of the wanted family size and whether the pregnancies were wanted at the time they took place should form a further basis for the prediction of fertility. As the time of birth of a woman's first child will influence the time of giving birth to succeeding births, then the time and desirability of pregnancy leading to the birth of this child will be a relevant basis for analysis. Simultaneously, the time of birth of this child must be supposed to have a very close connection with the living conditions of the families.

\section{The Sample}

The basis of this analysis is a survey which was carried out in the spring of 1970 by The Danish National Institute of Social Research, the Danish Bureau of Statistics and the Public Health Board. The study is based on 
interviews with 2397 married women from the age of 15 to 49 years old, 314 unmarried women and 330 husbands of the 20-29-year-old married women. The selection of persons to be interviewed was made in the first instance by choosing a number of municipalities scattered all over the country. Then the persons to be interviewed were selected from inhabitants of these municipalities. An error in the original sample has, however, involved that all persons living in the three metropolitan boroughs Copenhagen, Frederiksberg and Gentofte who were chosen for interviews were omitted. The questionnaire used and the interviewed women's responses to the individual questions, distributed according to age cohorts, appear in Study No. 22: "Some Aspects from the Fertility Investigation» published by The Danish National Institute of Social Research. A number of more detailed analyses of factors influencing family constellation and the size of the family are expected to be published at a later date.

\section{Pregnancy Resulting in the First Child}

The time interval between first marriage and birth of the first child, the spacing of the first child, is based on information from the interviewed women about the time of contraction of first marriage and the time of birth of the first child respectively. On the basis of this information the time interval in months has been calculated by means of Electronic Data Processing programmes specially made for this purpose.

It appears from these calculations that 6 per cent of all married women had their first child earlier than one year before marriage. 6 per cent had the child one year or less before marriage. Moreover 28 per cent gave birth to their first child within the first 8 months of marriage, 9 per cent after 9-11 months, whilst one-fifth had their first child after one to two years of marriage. In this percentage basis are included women who had not yet given birth. This group constitute 11 per cent of all married women in the survey.

The married women comprised by the survey who had had their first child were asked, whether the pregnancy resulting in this child, was wanted when conception took place. The question asked, read as follows: »One does not always become pregnant when one expects to. When you became pregnant and were going to have your first baby, was pregnancy then "wanted, but too early", "wanted and convenient», "wanted, but too late» or "not wanted»? This question aims to elucidate whether the first child was wanted when the woman conceived. As revaluations in the woman's attitude must to a large extent be expected to take place between the time of conceiving and the time of birth the question does not elucidate the extent of wanted and unwanted first-time births. As the woman may have had an abortion or given birth to a stillborn child before the first living 
birth, the question does not necessarily concern the first pregnancy. The question is, however, primarily relevant to the elucidation of the degree to which it has been possible for the women to realize their wishes as to the times of conception. Inability to realize these wishes can result from both unwanted and unintended pregnancies and also from reduced fecundity. Only 54 per cent of all married women with at least one child stated to have had their first child after a pregnancy which was wanted at the time it occurred. 26 per cent stated that pregnancy had been wanted, but that it occurred too early; 4 per cent said that pregnancy had occurred at too late a date, but as many as 16 per cent stated that pregnancy had been unwanted, cf. Table 1.

The time interval between the contraction of marriage and the birth of the first child seems to be one of the most decisive factors as to whether the woman has stated that pregnancy of the first child was wanted and planned at the time when it occurred. It seems to be of special importance whether the woman was married when she became pregnant.

A very noticeable difference in the attitude toward pregnancy among women who have had their first child before and after the ninth month of marriage respectively appears from Table 1 . Also there is a dividing line in attitude between women who had the child before and after four years of marriage. Of all women who became pregnant after marriage not less than 77 per cent indicate that pregnancy was wanted at the time when it occurred, or

$\mathrm{Table}$. Desirability of pregnancy resulting in the first child in per cent distributed according to the spacing of this child.

Spacing of first child

Pregnancy of first child wanted and planned

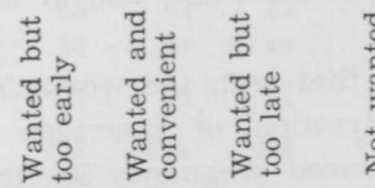

$\begin{array}{lrrrrrr}\text { Minus } 175-\text { minus } 13 \text { mths } & 29 & 13 & - & 58 & 100 & 110 \\ \text { Minus } 12-\text { minus } 1- & 46 & 19 & - & 35 & 100 & 127 \\ 0-8 \text { mths } & 49 & 27 & 0 & 24 & 100 & 624 \\ 9-11- & 20 & 75 & 2 & 3 & 100 & 158 \\ 12-24- & 13 & 83 & 2 & 2 & 100 & 378 \\ 25-48- & 4 & 89 & 6 & 1 & 100 & 218 \\ 49 \text { mths and more } & - & 57 & 42 & 1 & 100 & 88 \\ \text { TOTAL } & 26 & 54 & 4 & 16 & 100 & \\ \text { Number } & 514 & 874 & 63 & 252 & & 1703\end{array}$

NB The signature - indicates that observations do not exist, whereas the signature 0 indicates that the percentage is lower than 0,5 . 
too late. This is the case of not more than 27 per cent of pregnancies which occurred before marriage and of less than 20 per cent of pregnancies resulting in first-time births prior to the contraction of marriage. Although the dividing line around the ninth month of marriage is very noticeable the general findings are that the percentage of intended pregnancies rise to nearly loo per cent the longer the woman has been married. Yet no less than 42 per cent of the women who had the child after more than four years of marriage state that pregnancy was wanted at an earlier date.

\section{Attitude to Spacing of First Child}

The actual spacing of the first child differs considerably from the married women's attitude to what spacing of the first child they consider ideal. In order to elucidate the women's attitude to the spacing, one of the questions was: "How long an interval do you think there should be between marriage and birth of the first child?»

It appears that only 7 per cent think that the interval from the contraction of marriage till the birth of the first child should be less than twelve months; 69 per cent find that the length of the period should be one to two years, whilst 20 per cent are of the opinion that it should be more than two years. Compared with this, 49 per cent had the child before the end of the first year of marriage including women who had the child before marriage. Among women who conceived at the wanted time, a relatively great proportion had their first child at the time which all women in the sample considered ideal.

\section{The Woman's Age, Age at Marriage, and at the Time of Giving Birth.}

The analysis reveals that both the woman's age at the time of the interview and at the contraction of marriage has relation to the question whether she has experienced pregnancy leading to the first child as wanted at the time it occurred. It appears that a larger percentage of the women who married early had given birth to their first child. These women have also relatively often been pregnant at marriage, or they have had the child shortly before. Of the married women who married younger than 20 years old, more than half were pregnant when they married. This was also the case of one-third of the women who married at the ages of 20 to 21 , of just under one-fifth who married at the ages of 22 and 29 , but of less than one-tenth of the women who married when they were 30 years or more. Among the women in the last-mentioned group it was found, however, that nearly one-fourth had their first child more than twelve months before marriage. 
As mentioned, the woman's experience of pregnancy is correlated with the woman's marriage age and with the spacing of the first child. One might assume that one of these correlations was spurious. The correlation between the woman's marriage age and the woman's statement of the desirability of pregnancy could be connected with the different spacing of the first child. If it is not a question of spurious correlation, it must be examined whether the spacing and the marriage age are both of independent importance for the woman's experience of pregnancy, or whether the spacing combined with the marriage age is a more decisive factor of this. Thus the woman's marriage age combined with the spacing constitutes a measure for the woman's age at the birth of the child. This distinction will especially be relevant to the question whether the desirability of pregnancy shall primarily be considered in connection with circumstances connected with the establishment of the family or primarily with the woman's own education/training and her employment on the labour market.

$\mathrm{Table} 2$. The percentage of pregnancies resulting in the first child occurring at the wanted time, by the woman's age at marriage and spacing of the first child.

Spacing of first child

The woman's age at marriage

\begin{tabular}{|c|c|c|c|c|c|c|}
\hline & $\underset{\sim}{\stackrel{2}{\infty}}$ & 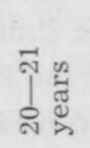 & 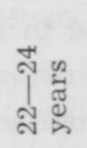 & 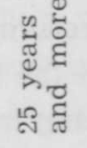 & Total & Number \\
\hline Minus $175-$ minus $13 \mathrm{mths}$ & 1 & 9 & 13 & 19 & 19 & 110 \\
\hline Minus $12-$ minus $1 \mathrm{mths}$ & 2 & 17 & 23 & 77 & 13 & 127 \\
\hline $0-8 \mathrm{mths}$ & 14 & 31 & 23 & 59 & 27 & 623 \\
\hline $9-11-$ & 73 & 79 & 71 & 76 & 75 & 158 \\
\hline $12-24-$ & 73 & 86 & 84 & 86 & 83 & 377 \\
\hline $25-48-$ & 89 & 92 & 88 & 87 & 89 & 218 \\
\hline $49 \mathrm{mths}$ and more & 64 & 63 & 64 & 43 & 57 & 88 \\
\hline TOTAL & 31 & 55 & 61 & 63 & 54 & \\
\hline Number & 438 & 577 & 495 & 191 & & 1701 \\
\hline
\end{tabular}

Whether the pregnancy leading to the first child was wanted at the time it occurred seems to be connected with the spacing as well as the woman's marriage age. It appears from Table 2 that irrespective of the women's marriage ages, the births have more often been wanted at the time they occurred, the later in marriage these took place. It is found, however, that women who have been married for more than four years before the birth of the first child - regardless of age at marriage - have frequently stated that pregnancy occurred at too late a date. Among the group of women who had their first child within four years of marriage the spacing is more closely connected with the tendency for women 
with an early marriage age to state pregnancy to be wanted at the time of occurrence than for women with a late age at marriage.

Among the women who married at the ages of less than 20 years old and who had the child before marriage, only a few stated that pregnancy had been wanted at the time when it occurred. A considerably larger number of the women who had married at a later age stated this to be the case.

This must be seen in relation to the married women, irrespective of the spacing of the first birth, having more frequently conceived at the wanted time the older they were at the contraction of marriage. As will be seen from Table 2 this connection is particularly pronounced for the births which took place before the ninth month of marriage.

The married women with the highest age at marriage and the longest spacing of the first child had the highest age at the birth of the first child, while the women with the shortest spacing of the first child and the lowest age at marriage had the lowest age at the birth of the first child. From Table 2 one can more-over get an impression of whether the woman's age at the birth of her first child was connected with pregnancy being wanted at the time when it occurred. As both spacing and the woman's age at marriage, as mentioned, are connected with the question whether the woman has experienced pregnancy as desired at the time it occurred, also the woman's age at her first birth will be connected with this. If the woman's age is of importance in this connection, it must, however, be presumed to be limited and primarily be dependent on the spacing of the time of the birth of the first child and the woman's age at marriage, where the spacing must be considered to be the most important factor.

The investigation is as mentioned a cross-section survey. Therefore the younger age groups will only be represented by women who married young, whereas women among older age groups have married at different ages. A comparison between the ability of the different age groups to have conceived at the wanted times must therefore necessarily be made between women who were married at the same age. This is a direct consequence of the clear connection of the age at marriage and the woman's statements of whether the pregnancies were wanted at the times they occurred.

From such an analysis it appears that the younger age groups to a considerably larger extent than the older ones have been able to avoid an unwanted pregnancy of the first child. It is also found that the married women in the individual age groups have more frequently had their first child from an unwanted pregnancy the earlier they married. Yet the age at marriage is more closely connected with this among the older than the younger age groups.

\section{Subsequent Pregnancies and Expected Family Size}

A correlation is found between the women's statements of the desirability of the first pregnancy and the following ones. Among the group of married women who had their first child after an unwanted pregnancy, a relatively large propor- 
tion, i.e. 85 per cent, have had a second child. This child has also relatively frequent been born as a result of unwanted pregnancy. This is the case of no less than 22 per cent in this group of women whose pregnancies resulted in the birth of the second child. Of the married women wanting pregnancy leading to the first child at the time when it occurred, 76 per cent had given birth to a second child. The largest proportion who became pregnant with the second child at the wanted time was found among women in this group. Only three per cent stated that the pregnancy of the second child was unwanted. On the other hand, of the married women who became pregnant with their first child at too late a date, only 53 per cent had had a second child. Of these women nearly one-third said that also the time of pregnancy for this child had occurred at too late a date.

This must be seen in connection with the fact that these groups of married women expect to have a different number of children. In the survey the expected number of children is an expression of the number of children the women had born at the time of the interview and the total number of further expected births. This expected family size is for all women most frequently two or three children and 50 per cent of these women expect to have two children or less. This proportion is also found in the group of women who had their first child at the wanted time. On the other hand the married women for whom pregnancy resulting in the first child was unwanted expect more births than the other women. Only 35 per cent expected to have two children or less, whereas 32 per cent, compared with 17 per cent of all married women, expect to have at least four children. In the group of married women, who stated that pregnancy resulting in the first child occurred at too late a date, contrarily a relatively small family size is expected. However, the smallest family size is expected by women who had not yet had their first child at the time when the interview took place. In this group there is a comparatively large number of older women. This group represent to a large extent women, who owing to a higher age or an established role, do not wish to change their occupational or family pattern, or who owing to subfecundity have no possibility of having children.

\section{Some Social Inequality Aspects}

The woman's age at marriage and the spacing of her children are both supposed to determine and be determined by economic, social and cultural factors. As might be expected, married women with schooling of longer duration have married at a later age than women with schooling of shorter duration. As the woman's schooling and possibly the birth of her first child will be closely connected with her possibilities and wishes of completing a professional education or vocational training, it is not surprising to find a close connection between 
the time of the contraction of marriage and the woman's professional education or vocational training.

At the same time the married women without vocational training have the shortest spacing as to the first child. No less than 17 per cent in this group have had the child before the marriage was contracted, whilst 33 per cent have had the child within the first eight months of marriage. Of the married women having served an apprenticeship, the corresponding proportions are 4 per cent and 20 per cent respectively, whilst in the group of women who have a theoretical education of not less than three years, the figures are 0 per cent and 11 per cent respectively. The last-mentioned group has the best opportunities on the labour market and presumably for that reason the greatest aspirations with a view to plan pregnancies at wanted times. Also a selective recruiting may have taken place so that women with unwanted pregnancies have had reduced possibilities of getting an education of longer duration. On this background it is found that married women without any vocational training have more often stated the pregnancy of the first child as being unwanted. This is probably due to a considerable difference in the sexual and contraceptive behaviour of the groups. Of married women with at least one child, 20 per cent of pregnancies leading to the first child were unwanted in the case of women without any vocational training, as against only 7 per cent among women having served an apprenticeship, and 8 per cent among women with a theoretical education of not less than three years.

Of the professionally well-educated women a very large proportion have married at a relatively late age, and at the same time they have a long spacing as to the first birth, where pregnancy was often wanted. These women have good opportunities on the labour market and have at the same time often married men who are economically well-off in society. Thus a large proportion has married supervisory employees, a smaller proportion subordinate employees. On the other hand it is found that married women without any vocational training have often married at a very early age and relatively often because of unwanted pregnancy. These women have often married men who, like themselves, have no vocational training, for which reason the family as a whole rank fairly low on the economic ladder. Of these women with no vocational training, 43 per cent have married men from the working class, of which the largest proportion were unskilled workers. The husband as well as the wife from this group have often their educational and occupational possibilities hampered by unwanted pregnancy.

Of all the women who at the time of the interview were married to unskilled workers, only 3 per cent represent families in the upper fourth of the income distribution of all families in the survey. This proportion was 65 per cent among the women married to supervisory employees, 26 per cent among the women married to subordinate employees, and 13 per cent among the women married to skilled workers. For married women with no vocational training, the opportunities on the labour market and the economic conditions of the families have 
been relatively modest. Among these, a large proportion has not been able to determine when pregnancies should occur. At the same time society has had a restrictive legislation on abortion.

For the individual family in industrialized society a birth problem can therefore still exist - a birth problem which it is not possible to recognize merely through a traditional demographic analysis. This problem can be said to exist as long as it is not possible for practically all women to have their children at the time they want to. This birth problem concerns both unwanted and unintended pregnancies as well as pregnancies, which in the woman's own opinion occur too late.

\section{Unwanted Pregnancies and the Desire to have Children}

The birth problem in society has mostly been considered in the light of the birth rate, a very high as well as a very low birth rate have been considered a social problem. In particular the increased supply of more effective contraceptives and the desire to liberalize the abortion law have led to a debate whether as a consequence of this a considerable reduction in the birth rate can be expected. On the background of the frequent occurrence of unwanted pregnancies previously observed, the complex of problems will especially be related to the question whether the unwanted pregnancies have expressed that a large proportion of married women had desired to get fewer children.

In order to investigate this, all married women were asked how many children they would like to have in all, if they could start their matrimonial life all over again and were free to choose. It is remarkable how the answers show that on an average the married women wish to have more children than they expect to get. Among women with at least one child no great differences were found as to the number of wanted children according to the woman's statement of whether pregnancy resulting in the first child was wanted at the time when it occurred. But a great difference was - as already mentioned - found with regard to the expected family size. This indicates a very common ideal that a Danish family should have 2 or 3 children, but that a large proportion has not been able to realize this family-size earlier.

\section{Summary and Conclusion}

This article gives a summary of some of the results based on interviews of 2397 married women from fertile age groups in Denmark in the year 1970. The time of birth of the first child were analyzed in relation to the demographic build-up and the living conditions of the family. It has further been a desire to investigate whether a noticeable change in fertility can be expected in Danish society with improved possibilities for family planning and induced 
abortion. In Denmark oral contraceptives was introduced in 1966, while free abortion has been approved from 1973 .

A close connection was found between the expected family size and the family's living conditions on the one hand and both the time of the woman's contraction of marriage, the birth of the first child, and the desirability of pregnancy on the other. Married women with early contraction of marriage more often seem to expect a large number of children and often because they have experienced unwanted pregnancies. These women have often married men who, like themselves, had no vocational training. As a whole these families rank fairly low on the economic ladder.

Though it cannot be immediately assumed that improved possibilities for family planning and induced abortion will mean any noticeable decline in the birth rate as a direct consequence that a large group of women appear to have had more children than they wanted. A very common ideal is indicated that a family with two or three children is the wanted size and only a small proportion expect to have more than three children. On the other hand a change in the time of giving birth to the first child and hereby the following one(s) can be expected. This change will primarily involve that the first child will be born later in the marriage than was previously the case. The sudden fall in fertility which Danish society observed in the year 1967 can especially be supposed to be related to a previous difference between the women's behaviour by the time of the occurrence of pregnancies. This fall in fertility must be expected to have been of temporary nature, as it must primarily be assumed to concern the spacing of the births and only to a limited extent lead to a reduction of the total birth level. 